\title{
ARE VARIATIONS OF GLYCATED HEMOGLOBIN GIVEN BY THE FREESTYLE DEVICE ACCURATE?
}

\author{
Y. Senterre ${ }^{2}$, K. Fombellida², E. Cavalier ${ }^{1}$, N. Paquot ${ }^{2}$, P. Delanaye ${ }^{3}$ \\ ${ }^{1}$ Clinical Chemistry, CHU Sart Tilman, University of Liège, \\ 2 Metabolic Diseases, CHU Sart Tilman, University of Liège, \\ 3 Nephrology, CHU Sart Tilman, University of Liège
}

\section{BACKGROUND-AIM}

Continuous glucose monitoring (CGM) by interstitial glucose fluid monitoring is a major recent improvement in the global care of diabetic patients. The FreeStyle Libre (FSL) allows CGM, but can also provide an estimated glycated hemoglobin (eA1C) based on serial interstitial glycaemia. Several studies showed a good correlation between eA1C and measured glycated hemoglobin (A1C) in cross-sectional designs.

In the current study, we studied the ability of the FSL to correctly estimate such variations of A1C.

\section{METHODS}

Patients from our University hospital with the following criteria were considered: type 1 diabetes with FSL and two values of $\mathrm{A} 1 \mathrm{C}$ within an interval of $\mathbf{8 0}$ to $\mathbf{1 0 0}$ days, values obtained from FSL (Abbot Diabetes Care) on one part and the laboratory (HPLC, HA8180, Menarini) on the other part.

The values should be obtained within the same period ( \pm 8 days). According to biological variation of $\mathrm{A} 1 \mathrm{C}$ measurement, a change in $\mathrm{A} 1 \mathrm{C}$ concentration of minimum $\pm 6 \%$ was considered as clinically significant. Accordingly, the patients were classified with the two techniques as stable, "improving" (value decreased) or "worsening" (value increased).

\section{RESULTS}

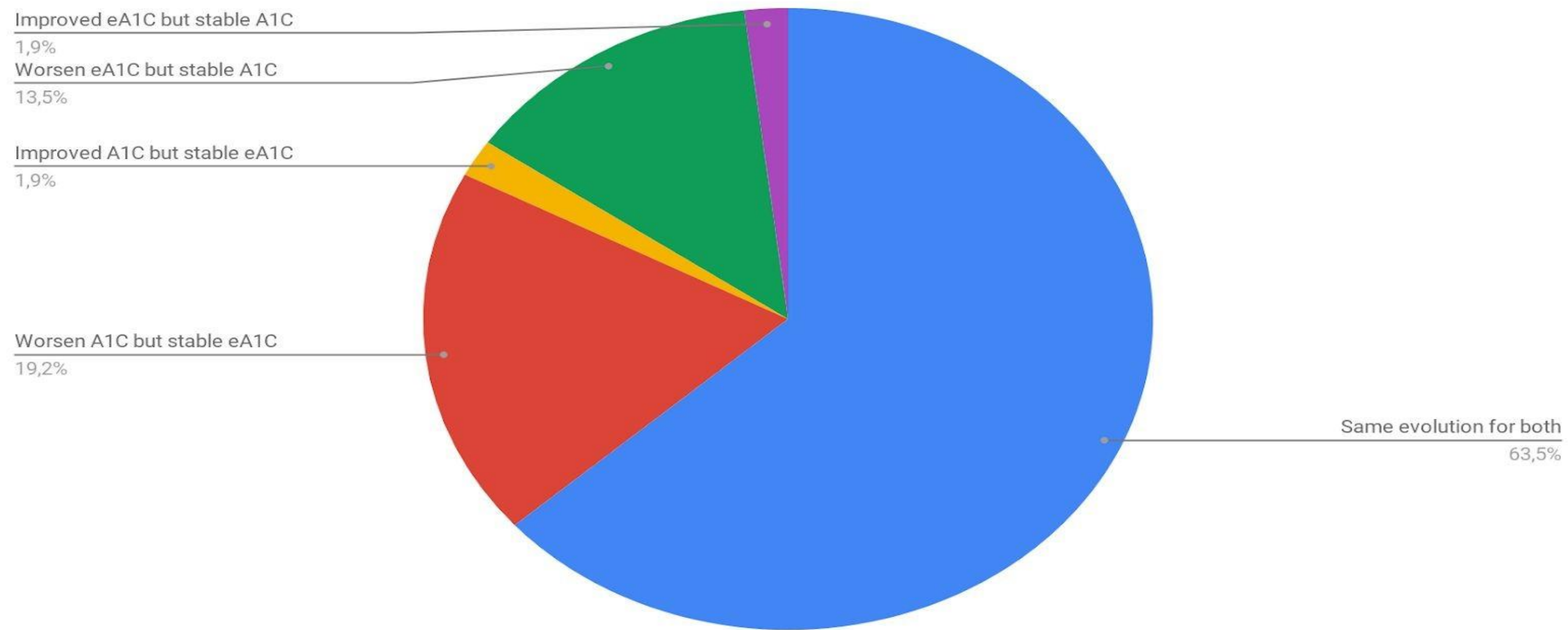

\section{CONCLUSION}

In this study, we showed that variations of A1C are correctly assessed by eA1C in two-third of the patients. In the remaining third, discrepancies are observed between stable and others, but "improving" patients are never classified as "worsening" (or the inverse). 